\title{
A community based stroke register in a high risk area for stroke in north west England
}

\author{
Xianglin Du, Joan Sourbutts, Kennedy Cruickshank, Alison Summers, Nick Roberts, \\ Elizabeth Walton, Stephen Holmes
}

\section{Clinical Epidemiology \\ Unit, School of Epidemiology and Health Sciences, University of Manchester Medical School, Manchester M13 9PT \\ $\mathrm{X}$ Du \\ K Cruickshank \\ J Sourbutts}

Department of Public Health, East

Lancashire Health

Authority, Nelson,

Lancashire

A Summers

E Walton

Department of Medicine for the Elderly, Queen's Park Hospital. Blackburn, Lancashire

N Roberts

The Surgery, Earby, Lancashire

$S$ Holmes

Correspondence to:

Dr X Du, Centre on Aging, University of Texas Medical Branch, Galveston, Texas 77555-08600, USA or Dr K Cruickshank.

Accepted for publication May 1997

\begin{abstract}
Study objective-To develop a community based stroke register to assess the magnitude of the problem of stroke in an entire health district in a high risk area for stroke. Design-Community based stroke register from general practice data.

Setting-East Lancashire Health Authority with a 1995 population of 534287 .

Patients-The stroke register was developed and maintained for one calendar year in East Lancashire between 1 July 1994 and 30 June 1995. Efforts were made to include all patients who had a stroke during this period from participating general practices, using several sources of referral.

Main results-Of the district's 118 general practices, 93 (79\%) participated fully, covering a population of 405 272. A total of 932 strokes, including 642 first ever cases, were cross checked and confirmed, with only $50 \%$ from any single source, mainly the practices. The total stroke incidence rate was 1.60 per 1000 per year, adjusted for the England and Wales 1991 census population. The rate increased considerably with age from $0.88 / 1000$ for ages $50-54$ to $20.56 / 1000$ for ages $85-89$ years. From 50-74 years, the age specific incidence was higher in men, but overall it was higher in women $(1.87 ; 95 \%$ confidence interval $1.67,2.04$ per 1000$)$ than in men $(1.31 ; 1.15$, 1.47 per 1000$)$, and slightly lower than in Oxford a decade earlier. The rate also varied in different localities, with higher rates in the central towns of Hyndburn (2.05/ 1000), Blackburn (1.63/1000), and Burnley $(1.80 / 1000)$ and lowest values in rural areas (1.18/1000 in Pendle). Case fatality from stroke at 28 days was $34 \%$ and the hospital admission rate was high at $70 \%$. Conclusions-The multiple source registration method is required for a stroke register. Stroke incidence in this area was still high and there was considerable variation across the district. Case fatality rates were similar to those in previous studies.
\end{abstract}

\section{$(\mathcal{F}$ Epidemiol Community Health 1997;51:472-478)}

Studies of stroke incidence in a community provide perhaps the most reliable estimate of the continuing magnitude of the condition in terms of morbidity as well as fatality (which, crudely, is easier to measure). Perhaps most importantly, in a population based project the number of stroke patients who remain in the community rather than being admitted to hospital can be determined. If cases are registered from patients who are seen only by the general practitioners (GPs) and primary care teams as well as from other sources, such comprehensive notification generates proper data on stroke occurrence which should help in planning appropriate services.

There have been many studies of stroke incidence throughout the world over the past 40 years and these have contributed valuable information on secular trends for stroke. ${ }^{1-3}$ The few stroke register projects reported in the United Kingdom ${ }^{4-6}$ were undertaken in generally lower risk areas than the one studied here. The first was from Oxfordshire, a decade ago, and stroke mortality then was similar to the current level in north west England. ${ }^{4}$ In 1993, the standardised mortality ratio (SMR) for stroke was still 65 compared with 130 in north west England. ${ }^{7}$ A study in southern England found that one area in inner London (West Lambeth) had a high incidence and two other areas moderate and low rates. ${ }^{6}$.

Information about stroke incidence, prevalence, severity, outcome, and management has been identified as a National Health Service Research and Development strategy priority, and community based stroke registers provide the basis for addressing these issues. Here, we describe how stroke registration was begun, maintained, and ascertained in a primary care setting, and the results of this in the health district of East Lancashire.

\section{Methods}

\section{STUDY POPULATION AND STROKE REGISTER} DEVELOPMENT

This study aimed to include all general practices in the East Lancashire Health District, north west England. The district includes the towns of Blackburn and Burnley and surrounding rural areas and had a total population of 534287 in mid 1995 (from GP age-sex registers). Initially, we wrote to all local GPs in the area inviting them to participate, and $87 \%(103 / 118)$ practices accounting for $83 \%$ of 276 practitioners agreed to do so. A series of individual and group meetings were held and a project steering group, including GP representatives from the two district audit teams then operating, was set up. Participating GPs were asked to record prospectively, through a contact person in the practice (usually a receptionist or practice nurse), all cases of stroke or transient ischaemic attack (TIA) that occurred between 1 July 1994 and 30 June 
1995. The study nurse (JS) and study physician (XD) contacted all practices fortnightly, both by telephone and then subsequently by personal visit for any cases recorded, so that in the process of ascertaining and documenting the stroke, awareness and impetus were also maintained. Medical concerns were discussed when necessary with senior colleagues on the steering group.

All stroke patients ("cases") usually resident in East Lancashire and registered with the participating GPs were included, even if the patient's stroke occurred outside the study area. Those not registered with participating GPs were excluded. All cases of stroke (first ever and recurrent) occurring over the one year period were registered. "Possible strokes" and TIAs were also included so that the diagnosis could be confirmed or refuted. The first ever confirmed strokes were used to calculate the stroke incidence rate and these data were also used for a subsequent case-control study on the risk of stroke in relation to the quality of blood pressure detection and control which has been reported elsewhere. ${ }^{8}$

DEFINITION OF STROKE

The World Health Organization diagnostic criterion $^{9}$ was used. This defines a stroke as "rapidly developing clinical signs of focal (or global) disturbance of cerebral function, lasting more than 24 hours or leading to death with no apparent cause other than that of vascular origin". This diagnosis included patients presenting with clinical signs and symptoms suggestive of subarachnoid haemorrhage, intracerebral haemorrhage, or cerebral ischaemic infarction, under International Classification of Diseases 9th revision codes of 430 to $438 .^{10}$ TIAs were recorded on the register in a separate category. Information about the diagnosis of stroke depended on the documented diagnosis made by the patient's GP and/or hospital doctors.

\section{Estimated number of expected strokes}

The available SMRs for the years before the study (1991-93) were examined. We used the Oxford study's experience, where SMRs were half those here, adjusting for the continuing decline in stroke rates across Britain and doubling the numbers of local deaths used in calculating the SMRs to include non-fatal events. We estimated that there should be 600 700 first ever strokes across the health district.

\section{Confidentiality, case ascertainment, and cross} checks

The study was approved by the East Lancashire Ethics Committees. A major issue was to ensure and maintain confidentiality of case identity or details at all times. This was done by holding patient and GP identifying data separately from the questionnaires in the East Lancashire District Medical Audit Advisory Group office.

Cases were ascertained and cross checked through several sources, including the following:

- General practices: GPs were asked to report all the possible stroke patients, including
KEY POINTS

- A community based stroke register was developed and maintained for a full calendar year in $79 \%$ of general practices in East Lancashire.

- Total stroke incidence, age and sex standardised to the England and Wales 1991 population, was 1.60 per 1000 per year.

- Geographical variations in stroke rates exist within the district.

- To inform local efforts on stroke prevention and care, similar datasets can become routinely available in an era of computerised recording.

TIAs, through their contact person. They used a standard stroke register sheet to fill in any possible strokes cases that occurred. In addition to the fortnightly telephone calls to seek all "new strokes" during the previous two weeks, we also asked again about new cases while we were visiting that surgery to verify cases.

- Hospital ward registers and discharge data sets: clinical audit staff checked with each ward in the three main hospitals in the district (Blackburn Royal, Queen's Park, and Burnley General Hospitals) at least once a month from ward log books for new stroke cases which were then reported to our research nurse. The local stroke association was also asked to report patients to us. Further cross checking was done from the statutory hospital activity analysis minimum data set, which contained all discharge diagnoses from East Lancashire hospitals. These data were cross checked against the reported cases from the hospital staff. When possible stroke cases were found, the name of their GP was recorded. If the practitioner was among those participating in the project, an appointment was made to visit the relevant surgery to check the details against the practice register and the patients' notes.

- Death certificates and coroners: East Lancashire Health Authority Information Centre held the death certificates of all patients who had died in the district. Death certificates were checked every two months. All possible strokes and GP details were recorded. Appointments were made to visit the local family health services authority in Preston, Lancashire (where all notes of dead cases were sent) to check the original case details.

- Rehabilitation services (physiotherapists etc), nursing homes, support services (local stroke association and family support group): these groups were asked to help in reporting possible stroke cases. They were initially contacted by letter and then visited during the year by the research nurse.

VERIFICATION AND DATA COLLECTION

If there was a positive documented note detailing the stroke event from the hospital doctors or GPs fulfilling the stroke definition, it was confirmed by a visit to the GP's surgery or the family health services authority. For all con- 


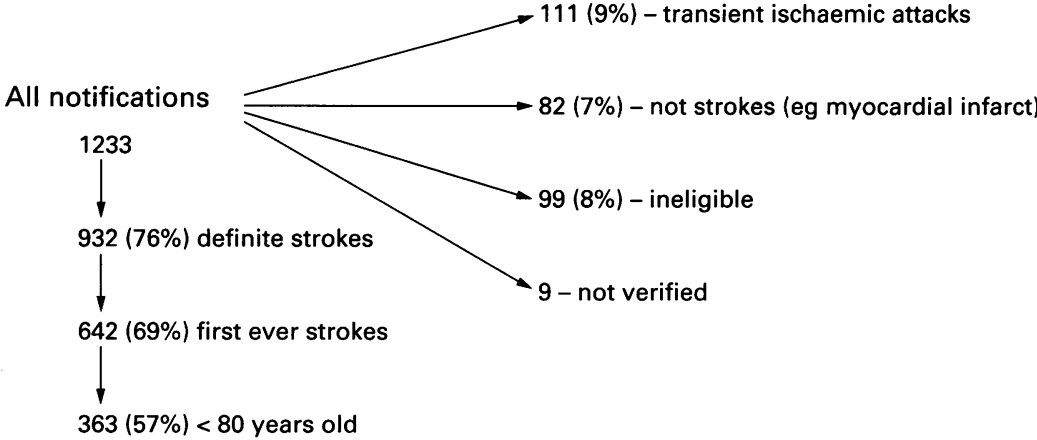

Figure 1 Stroke register in East Lancashire between 1 fuly 1994 and 30 June 1995.

Table 1 Multiple sources of referrals for a stroke register in East Lancashire

\begin{tabular}{lll}
\hline No of sources of referral & $\begin{array}{l}\text { All strokes } \\
(n=932) \text { No (\%) }\end{array}$ & $\begin{array}{l}\text { First ever stroke } \\
(n=642) \text { No (\%) }\end{array}$ \\
\hline From any single source & $461(49.5)$ & $323(50.3)$ \\
From 2 sources & $277(29.7)$ & $185(28.8)$ \\
From 3 sources & $163(17.5)$ & $113(17.6)$ \\
From 4 sources & $26(2.8)$ & $17(2.6)$ \\
From 5 sources & $5(0.5)$ & $4(0.6)$ \\
Total & $932(100)$ & $642(100)$ \\
\hline
\end{tabular}

firmed strokes, the one page registration form, including the relevant demographic data and details of the stroke, was filled in by the research nurse (JS) or the study physician (XD) as soon as possible after the case had been notified.

All data were stored confidentially on a database in the University of Manchester Medical School Clinical Epidemiology Unit.

ANALYSIS

The term "stroke attack rate" refers to both first ever and recurrent strokes or all strokes occurring during the one year period. "Incidence rate" is restricted to first ever strokes. "Case fatality rate" is defined as the proportion of events which were fatal either within 28 days of onset or within 3 months of onset. Rates were age and sex standardised against the England and Wales 1991 census population.

\section{Results}

PARTICIPATING POPULATION

Among the health district's total of $118 \mathrm{GP}$ practices, only 15 (13\%: 47 practitioners) did not participate at the outset, giving a high response rate of $87 \%$ for initiating the stroke register. Stroke cases from a further $10 \mathrm{GP}$

Table 2 Breakdown of those cases referred from a single source only in the stroke register

\begin{tabular}{|c|c|c|c|c|}
\hline \multirow[b]{2}{*}{ Sources of referrals } & \multicolumn{2}{|c|}{$\begin{array}{l}\text { Strokes single referred by source } \\
\text { only }\end{array}$} & \multicolumn{2}{|l|}{ All referrals } \\
\hline & $\begin{array}{l}\text { All strokes } \\
(n=461) \text { No } \\
(\%)\end{array}$ & $\begin{array}{l}\text { First ever stroke } \\
(n=323) \text { No } \\
(\%)\end{array}$ & $\begin{array}{l}\text { All strokes } \\
(n=932)^{\star} \text { No } \\
(\%)\end{array}$ & $\begin{array}{l}\text { First ever stroke } \\
(n=642) * N o \\
(\%)\end{array}$ \\
\hline General practitioners & $220(47.7)$ & $158(48.9)$ & $525(56.3)$ & $359(55.9)$ \\
\hline Minimum data sets & $94(20.4)$ & $68(21.1)$ & $460(49.4)$ & $318(49.5)$ \\
\hline \multicolumn{5}{|l|}{ Death } \\
\hline certificates/coroners & $107(23.2)$ & $65(20.1)$ & $385(41.3)$ & $237(36.9)$ \\
\hline Hospital wards & $25(5.4)$ & $20(6.2)$ & $183(19.6)$ & $150(23.4)$ \\
\hline \multicolumn{5}{|l|}{ Physio \& speech } \\
\hline therapists & $11(2.4)$ & $8(2.5)$ & $51(5.5)$ & $34(5.3)$ \\
\hline District liaison team & $1(0.2)$ & $1(0.3)$ & $21(2.3)$ & $14(2.2)$ \\
\hline Nursing homes & $3(0.7)$ & $3(0.9)$ & $8(0.9)$ & $7(1.1)$ \\
\hline Total & $461(100.0)$ & $323(100.0)$ & & \\
\hline
\end{tabular}

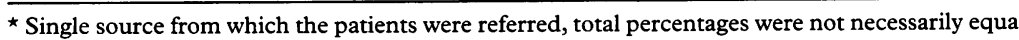
to 100 . practices (8\%: 24 practitioners) had been incompletely and/or inconsistently verified throughout the register and were therefore excluded. Thus, the remaining 93 represented a final total participation rate of $79 \%(93 / 118)$ for GP practices and $74 \%(205 / 276)$ for practitioners, serving a population of all ages of $405272(76 \%)$. This denominator for the stroke register had a similar age structure to that of the district's total population $\left(\chi^{2}=8.82\right.$, $6 \mathrm{df}, \mathrm{p}=0.184$ for total; $\mathrm{p}=0.758$ for men and 0.391 for women).

NOTIFICATIONS OF STROKES

There were 1233 individual notifications after removing the duplicated cases found by cross checks (fig 1). Of 1233 notifications, 932 were confirmed as definite strokes. This figure included $642(69 \%)$ first ever strokes, 290 (31\%) recurrent strokes, 111 TIAs, and 82 episodes that were confirmed not to be strokes; 99 were strokes but had not occurred in the one year study period and 9 were not verified because the patients notes were unavailable.

\section{REFERRAL SOURCES}

Only half of the stroke cases could be found from any single source of referral. Just over half the remainder were from any two sources with only $20 \%$ notified from three or more (table 1 ). For those referred from a single source only, nearly half were from GPs and only $6 \%$ were from hospital wards (table 2).

Analysis of cross checked individual referrals of all 932 strokes and 642 first ever strokes showed that most $(56 \%)$ were referred by the GPs, $50 \%$ were from hospital discharge data sets and $37-41 \%$ from the death certificates or coroners. Only $20-23 \%$ were referred to the register from hospital wards, and a further $5-7 \%$ were referred from physiotherapists or speech therapists, district liaison teams, or nursing homes (table 2).

\section{STROKE ATTACK RATE}

A total of 932 new strokes (first ever and recurrent strokes) occurred during the study period, giving a crude stroke attack rate of $2.30(95 \%$ confidence interval $2.15,2.45)$ per 1000 participating population $-2.00(1.80,2.19)$ for men and $2.60(2.38,2.82)$ for women. Age and sex adjusted attack rates against the England and Wales 1991 census population were 2.08 for men, 2.56 for women and 2.33 per 1000 per year for both.

AGE-SEX SPECIFIC FIRST EVER STROKE INCIDENCE A total of 642 first ever strokes occurred in the 93 participating GP practices (total population 405272 ), giving a total incidence of 1.58 per 1000 population. As expected, the incidence rates increased considerably with age in both sexes (table 3 ). From 50-74 years, the age specific incidence was higher in each age group in men than women, but overall it was greater in women $(1.87 ; 95 \%$ CI 1.67 , $2.04 / 1000)$ than in men $(1.31 ; 1.15,1.47 /$ 1000) This was lower, but not significantly so $(p=0.8)$, than the Oxford rates in the 1980s 
Table 3 Age-sex specific incidence rates for first ever stroke for all ages in East Lancashire, 1994-95

\begin{tabular}{|c|c|c|c|c|c|c|c|c|c|}
\hline \multirow[b]{2}{*}{ Age (y) } & \multicolumn{3}{|l|}{ Men } & \multicolumn{3}{|l|}{ Women } & \multicolumn{3}{|l|}{ Total } \\
\hline & $\begin{array}{l}\text { No of } \\
\text { population }\end{array}$ & $\begin{array}{l}\text { No of } \\
\text { strokes }\end{array}$ & $\begin{array}{l}\text { Rate } \\
(/ 1000)\end{array}$ & $\begin{array}{l}\text { No of } \\
\text { population }\end{array}$ & $\begin{array}{l}\text { No of } \\
\text { strokes }\end{array}$ & $\begin{array}{l}\text { Rate } \\
(/ 1000)\end{array}$ & $\begin{array}{l}\text { No of } \\
\text { population }\end{array}$ & $\begin{array}{l}\text { No of } \\
\text { strokes }\end{array}$ & $\begin{array}{l}\text { Rate }(/ 1000)(95 \% \\
C I)\end{array}$ \\
\hline$<50$ & 145302 & 11 & 0.08 & 136902 & 15 & 0.11 & 282204 & 26 & $0.09(0.06,0.13)$ \\
\hline $50-54$ & 11799 & 15 & 1.27 & 11038 & 5 & 0.45 & 22837 & 20 & $0.88(0.49,1.26)$ \\
\hline $55-59$ & 10305 & 13 & 1.26 & 9801 & 6 & 0.61 & 20106 & 19 & $0.94(0.52,1.37)$ \\
\hline $60-64$ & 9132 & 24 & 2.63 & 9115 & 22 & 2.41 & 18247 & 46 & $2.52(1.79,3.25)$ \\
\hline $65-69$ & 8224 & 40 & 4.86 & 9202 & 32 & 3.48 & 17426 & 72 & $4.13(3.18,5.08)$ \\
\hline $70-74$ & 7444 & 45 & 6.05 & 9361 & 43 & 4.49 & 16805 & 88 & $5.24(4.15,6.33)$ \\
\hline $75-79$ & 4403 & 34 & 7.72 & 6793 & 58 & 8.54 & 11196 & 92 & $8.22(6.54,9.89)$ \\
\hline $80-84$ & 3034 & 42 & 13.84 & 5889 & 80 & 13.58 & 8923 & 122 & $13.58(11.26,16.08)$ \\
\hline $85-89$ & 1383 & 27 & 19.52 & 3746 & 77 & 20.56 & 5129 & 104 & $20.56(16.42,24.13)$ \\
\hline$\geqslant 90$ & 540 & 13 & 24.07 & 1859 & 40 & 21.52 & 2399 & 53 & $21.52(16.21,27.97)$ \\
\hline Total & 201566 & 264 & $1.31^{\star}$ & 203706 & 378 & $1.87^{\star}$ & 405272 & 642 & $1.58(1.46,1.71)^{\star}$ \\
\hline
\end{tabular}

* Rates, after adjusting for England \& Wales 1991 census population were 1.36 for male, 1.83 for female, 1.60 for all. Rates, after adjusting for England \& Wales 1981 census population were 1.21 for male, 1.62 for female, 1.43 for all (allowing comparison with a previous UK study ${ }^{5}$ ).

(fig 2). Rates, age and sex standardised against the England and Wales 1991 census population, were 1.60 per 1000 per year-1.36 for men and 1.83 for women-and are also given standardised against the 1981 census for direct comparison against the Oxford rates $^{5}$ as discussed below.

\section{GEOGRAPHICAL DIFFERENCES IN STROKE}

INCIDENCE

After adjusting for the England and Wales 1991 census data, the stroke incidence rates in different towns varied from 1.18 in Pendle to a significantly higher 2.05 per 1000 per year in Hyndburn (table 4). The latter's rate was also higher than the whole of the health district's eastern subdistrict. In general, the rate in the Blackburn area was higher than in the Burnley area and central towns had higher rates than rural areas such as Pendle and Ribble Valley. Ethnicity was not a factor with only five stroke cases in people of Indian subcontinent origin. This was probably due to the younger age structure of this population, who are otherwise at considerable high general cardiovascular risk.

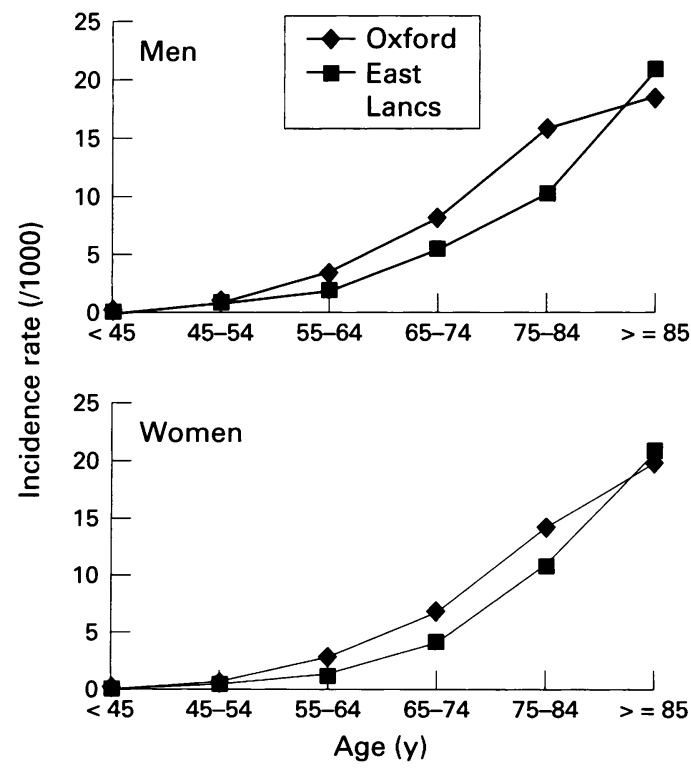

Figure 2 Comparison of the age specific stroke incidence rates in Oxford in 1981-86 and East Lancashire (Lancs) in 1994-95.
ADMISSION TO HOSPITAL

Of 642 first ever stroke patients, $448(69.8 \%)$ were admitted to hospital, meaning that 194 $(30.2 \%)$ stroke patients were cared for at home or in the community. Of the 448 admitted, 391 $(60.9 \%)$ were admitted within 24 hours of the onset of the stroke and $413(64.3 \%)$ within 1 week. Of 290 patients with recurrent strokes, $165(56.9 \%)$ were admitted to hospital.

CASE FATALITY

A total of 217 stroke patients died within 28 days from the onset, so the case fatality rate at 28 days was $33.8 \%$. The rate was higher in women than in men, but not significantly so. The case fatality rate within 3 months was $39.7 \%$. Among those $363(56.5 \%)$ patients aged less than 80 years old, the case fatality rates at 28 days and 3 months were $25.3 \%$ and $29.8 \%$ respectively.

\section{Discussion}

A stroke register provides more accurate estimates of incidence and mortality rates than other means such as official routine statistics. A community based incidence study is therefore the best way to evaluate the incidence of new strokes. It is important that a stroke register determines the incidence and profiles of stroke in a population, unbiased by hospital admission or outpatient referral practice. With over $50 \%$ of GP practices now computerised and recording major morbidity events, data collection and analysis should become routine. If these data can be brought together annually for stroke, it should be possible to generate reliable estimates of morbidity over many years. Nevertheless, in this study only $50 \%$ of cases were registered through the general practices alone.

The proportion of patients with strokes who are referred to hospital has varied from $17 \%$ to "almost all patients with a stroke" in different study areas. " The Oxfordshire community stroke project, based on a smaller number of cases and participating practices, reported a hospital admission rate of $55 \% .{ }^{11}$ A rate of $41 \%$ was recently reported in the study of stroke in the south of England (which included both an inner London borough (1985-89 SMR: 134 for West Lambeth and 108 for North Southwark) and a rural area (Tun- 
Table 4 Incidence rates for first ever stroke and geographical differences in East Lancashire Health Authority

\begin{tabular}{lccclc}
\hline $\begin{array}{l}\text { Geographical } \\
\text { area }\end{array}$ & Total population & $\begin{array}{l}\text { Participating } \\
\text { population }\end{array}$ & $\begin{array}{l}\text { No of } \\
\text { strokes }\end{array}$ & $\begin{array}{l}\text { Rate }(95 \% \text { CI) } \\
(/ 1000)\end{array}$ & $\begin{array}{l}\text { Adjusted } \\
\text { rate }\end{array}$ \\
\hline Blackburn & 145531 & 120583 & 178 & $1.48(1.26,1.69)$ & 1.63 \\
Hyndburn & 83567 & 80521 & 160 & $1.99(1.68,2.29)$ & 2.05 \\
Ribble Valley & 55143 & 55143 & 82 & $1.49(1.17,1.81)$ & 1.37 \\
Subtotal & 284241 & 256247 & 420 & $1.64(1.48,1.80)$ & 1.70 \\
Burnley & 97268 & 49909 & 92 & $1.84(1.47,2.22)$ & 1.80 \\
Pendle & 90767 & 68652 & 84 & $1.22(0.96,1.49)$ & 1.18 \\
Rossendale & 62011 & 30464 & 46 & $1.51(1.07,1.94)$ & 1.59 \\
Subtotal & 250046 & 149025 & 222 & $1.49(1.29,1.69)$ & 1.49 \\
Total & 534287 & 405272 & 642 & $1.58(1.46,1.71)$ & 1.60 \\
\hline
\end{tabular}

* Rates were adjusted for the England \& Wales' 1991 population.

bridge Wells (SMR: 70). ${ }^{6}$ In our study, the admission rate was much higher, but even so $30 \%$ of stroke patients were not admitted to hospital. Clearly, a hospital based register would not represent the true picture of stroke in the community.

This is the first stroke register in the north west of England, which has provided information for monitoring stroke incidence in this high risk area and offers the local GPs a picture of how many new strokes (first ever and recurrent) occur over a one year period. From this register, we were able to identify patients representative of all those with stroke in the population for detailed study. Our case-control study with the first ever stroke cases aged less than 80 years identified from this register, examined the relationship between the risk of stroke and the quality of blood pressure control in routine practice. ${ }^{8}$ It identified the fact that strict blood pressure control, to $<150$ and 90 $\mathrm{mmHg}$, minimised stroke risk in people even conservatively defined as hypertensive (two readings showing $>160$ or $95 \mathrm{mmHg}$ in GP notes within 3 months). Hypertension (whatever the definition $>140$ or $90 \mathrm{mmHg}$ ) conferred a risk of 2.5 for stroke, was the single most important determinant of stroke in this setting, and is clearly amenable to improved control.

\section{COMPLETENESS OF ASCERTAINMENT AND} DIAGNOSIS OF STROKE

Ascertainment

The actual number of strokes was close to the number estimated before the register was set up. All available sources of stroke cases seemed to have been checked so that total ascertainment across the district appeared to be reasonably complete. We also wrote to residential and nursing homes for information, but with over 200 in the district they could not all be monitored. The residents of these institutions would mainly be very elderly, and this would probably not have biased our findings in those $<80$ years old, although the total stroke register count might have been underestimated.

Surprisingly, only a few (20\%) stroke cases were notified from the hospital wards, although a total hospital admission rate of $70 \%$ was recorded. The "minimum contract" dataset, containing all discharge diagnoses from the district hospitals, provided $50 \%$ of stroke patients recruited, overlapping with the 56\% from GPs. These data seem reliable as very few strokes were "old" (not within the study period) or not confirmed as strokes when the medical notes were examined. Thus, referrals from both hospital admission and discharge data generated the total number of hospital stroke cases. Community service teams referred about $10 \%$ of patients. Half the patients identified were from two or more sources of referral (table 1), indicating that the multiple sources of referral for new stroke cases which occurred during the period are particularly important for the population based register.

The "minimum contract" dataset was similar to the Oxford record linkage dataset (of patients who die in or are discharged from a hospital in the Oxford region with a given diagnosis identified), which was previously shown to be important for complete case ascertainment. ${ }^{5}$ In the Oxford study, $85 \%$ of referrals were from GPs, $9 \%$ from hospital admission, and $2 \%$ from death certificates. ${ }^{5}$ In the London stroke register, ${ }^{6}$ only $17 \%$ of referrals were from GPs, $58 \%$ were from the project register or field workers, and $16 \%$ were from death certificates. The proportion of each referral source varied between studies depending on the speed and timing of notification and assessment. Eventually, all patients with a diagnosis of stroke may be identifiable from the GP's record as disease or death information is supposed to go to the GPs.

\section{Diagnosis of stroke}

The study was based on clinical diagnosis of stroke made by GPs and hospital doctors and no effort was made to subclassify types of stroke. Only $28 \%(76 / 267)$ of strokes were confirmed by computed tomography (CT) $(20 \%)$ or necropsy examination $(8 \%)$. This method was also used by other national or international stroke registers. ${ }^{6}{ }^{12}$ The clinical diagnosis of a stroke having occurred or not is known to be reliable. ${ }^{1314}$ For instance, in the Oxfordshire stroke study, of those patients with clinically definite first stroke, only $1.5 \%$ were found by CT to have non-stroke lesions. ${ }^{14}$ However, the diagnosis of types of stroke (haemorrhagic or infarct) was unreliable without CT. It was considered that international comparison of incidence rates for all types of stroke combined is valid. ${ }^{1}$ Therefore, in order to avoid possible errors in differentiating types of stroke, all types of stroke were combined in our analysis.

\section{APPROPRIATENESS OF DENOMINATOR}

The local GP population register for mid-1995 was used to calculate the incidence rate for stroke, the method used in the Oxfordshire community stroke project. $^{45}$ This GP population register was the most appropriate denominator, because, unlike the census data, each individual practice's register not only should be kept reasonably up to date but also refers directly to the population in which the cases arose and were cared for. 
STROKE INCIDENCE AND CASE FATALITY

In order to compare these current results with the Oxfordshire stroke incidence rate during 1981 and 1986 (table 1 and 3), rates were standardised against the England and Wales 1981 population and were $1.21 / 1000$ for men, 1.62 for women, and 1.43/1000 for both. Thus, incidence rates here were somewhat lower than that in Oxford 10 years ago (1.92/1000), but higher than in Rochester, USA, ${ }^{15}$ and in Auckland, New Zealand. ${ }^{16}$ It was not possible to assess by how much the incidence had declined over past decades in this traditionally high risk area for stroke because there have never been incidence data before. Our crude estimate of the number of first ever stroke cases prior to the register, originally based on the Oxford study and the 1991-93 SMRs for stroke in England, was 574 to 776 as shown in detail elsewhere. ${ }^{17}$ Our final register results (642 first ever stroke cases) are thus well within these upper and lower estimates.

As expected, the rates show a steep increase with increasing age and are higher overall in females compared with males, consistent with other stroke incidence studies. ${ }^{3518}$ Stroke case fatality has been declining in the past two decades, ${ }^{1920}$ and is one of the major reasons for the recent improvements in stroke mortality. However, case fatality has varied considerably between countries and regions in men and women. ${ }^{3}$ Case fatality in our study was close to the average rate $(30 \%)$ in the international MONICA study, but was higher than in other European countries such as Sweden and Finland and lower than in Germany and Italy. $^{3}$

\section{LOCAL GEOGRAPHICAL DIFFERENCES}

There were local geographical differences in stroke occurrence. The incidence was highest in Hyndburn and in central Burnley, but lower in the surrounding rural areas. This finding was consistent with the high SMRs in these areas reported in the annual public health report ${ }^{21}$ and supported the geographic pattern found in southern London. ${ }^{6}$ Hyndburn is an old industrial town - the site of major factories in the past. Burnley and Blackburn are the centres of both subdistricts and unemployment rates here were higher than other semirural or rural areas in the district. ${ }^{22}$ There were also some differences in smoking, obesity, and dietary pattern among these areas. ${ }^{21}$ All these factors might have contributed to the difference in risk of hypertension and stroke as previous studies showed that unemployment and poorer social class as well as an unhealthy lifestyle are associated with increased risk of stroke. ${ }^{23}{ }^{24}$ However, detailed reasons for the long standing regional variation are still unknown, although the varying prevalence of hypertension and its management over many years could well account for more than has previously been appreciated. ${ }^{25}$ It was not possible in this study to examine how health service availability, use, and quality and access to care affected stroke rates.
This is the first stroke register developed in the north west of England. There were no such data before in this region, and it is only now possible to monitor the incidence trends. The value of this dataset, as has been shown in other parts of the world, ${ }^{26}$ should be its help in achieving better understanding of the local natural history of stroke, which therefore becomes more relevant to all local health care staff. This register, although underfunded, was also not that costly (at about $£ 40000$ for 1.5 years development and surveillance), and there was good co-operation from existing primary care teams. It should also be possible to explore ways to allow similar datasets to become routinely available and less expensive in the era of computerised management, but these will always require some dedicated staff time and analysis.

We thank Dr A Hirst and Ms A Wilson of East Lancashire Medical Audit Advisory Group for their help; Dr Phil Medical Audit Advisory Group for their help; Dr Phil Hannaford and Professor Stuart Donnan for their support.
Special thanks to all participating general practitioners and their Special thanks to all participating general practitioners and their
primary care teams, hospital staff, community nurses and therapists, local stroke association members and the Family Health Services Authority in Lancashire. The study was funded in part by East Lancashire Health Authority.

1 Malmgren R, Warlow C, Bamford J, Sandercock P. Geographical and secular trends in stroke incidence. Lancet 1987;2:1 196-200.

2 Boysen G, Nyboe J, Appleyard M, et al. Stroke incidence and risk factors for stroke in Copenhagen, Denmark. Stroke 1988;19:1345-53.

3 Thorvaldsen P, Asplund K, Kuulasmaa K, Rajakangas AM, Schroll $M$. Stroke incidence, case fatality, and mortality in the WHO MONICA project. World Health Organization monitoring trends and determinants in cardiovascular disease. Stroke 1995;26:361-7.

4 Oxfordshire Community Stroke Project. Incidence of stroke in Oxfordshire: first year's experience of a community stroke register. $B M \mathcal{F}$ 1983;287:713-7.

5 Bamford J, Sandercock P, Dennis M, et al. A prospective study of acute cerebrovascular disease in the community: the Oxfordshire community stroke project 1981-86. 1 . Methodology, demography and incident cases of firstever stroke. F Neurol Neurosurg Psychiatry 1988;51:137380.

6 Wolfe CD, Taub NA, Woodrow J, Richardson E, Warburton FG, Burney PG. Does the incidence, severity, or case fatality of stroke vary in southern England? $\mathcal{F}$ Epidemiol Community Health 1993;47:139-43.

7 North Western Regional Health Authority. Deaths from strokes in the North Western Region: trends and variations in cerebrovascular disease mortality 1973-1990. v. Bulletin 4. Manchester: North West Regional Health Authority, 1992.

$8 \mathrm{Du} \mathrm{X}$, Cruickshank K, McNamee R, et al. Case-control study of stroke and the quality of hypertension control in northwest England. BMf 1997;314:272-6.

9 WHO MONICA Project Principal Investigators. The World Health Organization MONICA project (monitoring trends and determinants in cardiovascular disease): a major international collaboration. $\mathcal{f}$ Clin Epidemiol 1988;41:10514.

10 World Health Organization. Manual of the international statistical classification of diseases, injuries, and causes of death 9th ed. vol 1. Geneva: World Health Organization, 1977.

11 Bamford J, Sandercock P, Warlow C, Gray M. Why are patients with acute stroke admitted to hospital? BMF 1986; 292:1369-72.

12 Asplund K, Bonita R, Kuulasmaa K, et al. Multinational comparisons of stroke epidemiology. Evaluation of case ascertainment in the WHO MONICA stroke study. World Health Organization monitoring trends and determinants in cardiovascular disease. Stroke 1995;26:355-60.

13 Whisnant JP. The decline of stroke. Stroke 1984;15:161-8.

14 Sandercock P, Molyneux A, Warlow C. Value of computed tomography in patients with stroke: Oxfordshire Community Stroke Project. BMF 1985;290:193-7.

15 Millikan CH, McDowell F, Easton JD. Stroke. Philadelphia: Lea \& Febiger, 1987.

16 Bonita R, Anderson CS, Broad JB, Jamrozik KD, StewartWynne EG, Anderson NE. Stroke incidence and case fatality in Australasia. A comparison of the Auckland and Perth population-based stroke registers. Stroke 1994;25: 552-7. 
$17 \mathrm{Du} \mathrm{X}$. A community-based stroke register and a casecontrol study of stroke in relation to quality of hypertension control in Northwest England. Manchester: University of Manchester, 1997. PhD thesis.

18 Tuomilehto J, Sarti C, Narva EV, et al. The FINMONICA stroke register. Community-based stroke registration and analysis of stroke incidence in Finland, 1983-1985. Am $\mathcal{f}$ Epidemiol 1992;135:1259-70.

19 Harmsen P, Rosengren A, Tsipogianni A, Wilhelmsen L. Risk factors for stroke in middle-aged men in Goteborg, Sweden. Stroke 1990;21:223-9.

20 Wolf PA, D'Agostino RB, O'Neal MA, et al. Secular trends in stroke incidence and mortality. The Framingham study. Stroke 1992;23:1551-5.

21 East Lancashire Health Authority. Public health report 1993. Nelson: East Lancashire Health Authority, 1994.
22 Ashton J. The health of the north west of England. The report of the Regional Director of Public Health 1995. Manchester: North West Regional Health Authority, 1996.

23 Franks PJ, Adamson C, Bulpitt PF, Bulpitt CJ. Stroke death and unemployment in London. $f$ Epidemiol Community Health 1991;45:16-8.

24 Marmot MG, Poulter NR. Primary prevention of stroke. Lancet 1992;339:344-7.

25 Du X, Cruickshank JK, Sourbutts J, et al. Prevalence, treatment, control and awareness of high blood pressure among first-ever stroke patients in northwest England. $\mathcal{f}$ Hypertension 1996;14(suppl 1):S244.

26 Broderick JP, Phillips SJ, Whisnant JP, O'Fallon WM, Bergstralh EJ. Incidence rates of stroke in the eighties: the end of the decline in stroke? Stroke 1989;20:577-82. 